\title{
REMOVAL OF METHYLENE BLUE FROM AQUEOUS SOLUTIONS USING AS BIOSORBENT SARGASSUM MUTICUM: AN INVASIVE MACROALGA IN EUROPE
}

Eugenia Rubin, Pilar Rodriguez, Roberto Herrero, Javier Cremades ${ }^{\star \star}$, Ignacio Barbara ${ }^{\star \star}$ and Manuel E Sastre de Vicente*

Departamento de Química Física e Enxeñería Química I, ** Departamento de Bioloxía Animal, Bioloxía Vexetal e Ecoloxía. Universidade da Coruña, Alejandro de la Sota 1, 15008 A Coruña, Spain. *Corresponding author e-mail: eman@udc.es; Phone: (34) 981167000 (ext.2198);

Fax: (34) 981167065

\section{ABSTRACT}

Methylene blue adsorption on Sargassum muticum, an invasive macroalga in Europe, has been investigated using visible absorption spectroscopy. Different pre-treatments, protonation and chemical cross-linking with $\mathrm{CaCl}_{2}$ or $\mathrm{H}_{2} \mathrm{CO}$, have been tested in order to improve the stability as well as the adsorption capacity of the algal biomass. The equilibrium binding has been described in terms of Langmuir or Freundlich isotherms depending on the algal pre-treatment; from the maximum adsorption capacity values, an estimation of the algal specific surface area was made. Moreover, it has been found that adsorption kinetics can be described according to the first order Lagergren model, from which the rate constant and the adsorption capacity were determined. Finally, simple empirical equations were obtained to evaluate the amount of methylene blue removed at any initial concentration and reaction time. The results obtained have shown that this type of material has a high adsorption capacity for methylene blue dye, this feature together with the short times needed to reach the equilibrium suggest that Sargassum muticum can be used as a low-cost biosorbent in wastewater treatments.

Keywords: Biosorption, dye adsorption, Sargassum muticum, isotherms, adsorption kinetics.

\section{INTRODUCTION}

Biosorption processes have attached a great importance from an environmental point of view as they can be used to remove toxic compounds from industrial wastewaters. Many industries use dyes to colour their final products and their discharge into natural waters causes severe problems because they are toxic to aquatic life and damage the aesthetic nature of the environment. ${ }^{1}$ Moreover, these 
effluents are rather difficult to treat by conventional biological and physical-chemical techniques due to the complex structure of the dyes. Therefore, adsorption processes provide an attractive alternative for the treatment of coloured waters. ${ }^{2}$ Activated carbon is the most popular and widely used adsorbent, but there are certain problems with its use since it is expensive and its regeneration is difficult. For this reason, interest has been recently focused on low-cost materials, ranging from waste products from other industries to naturally abundant biomass: sewage sludge and peanut shell, ${ }^{3}$ silk cotton hull, coconut tree saw dust and coir pith, ${ }^{4}$ moss, banana pith and water hyacinth roots, ${ }^{5}$ parthenium plant, ${ }^{6}$ bacteria and fungi. ${ }^{7}$ In particular, marine algae are very promising materials to be used as biosorbents in wastewater treatment because they represent a cheap source of biosorbent, as they are readily available in large quantities, and it has been shown that they display a high metal binding capacity, ${ }^{8}$ mainly due to carboxylic and sulfonate groups from the algal polysaccharides.

The present work deals with the adsorption of methylene blue, a dye often used to characterize the capacity of an adsorbent, ${ }^{9}$ by Sargassum muticum, an alga which is a pest fouling organism that competes with the local fucalean species and may also interfere with the "sea industry". ${ }^{10}$ For this reason, it would constitute an ideal material to be used as biosorbent. In addition, to the best of our knowledge, studies of dye adsorption by algae are not available; therefore, to explore this promising field of biosorption is desirable.

In order to perform the adsorption experiments, different pre-treatments for the chemical modification of the biomass, among them protonation and chemical cross-linking with $\mathrm{CaCl}_{2}$ and $\mathrm{H}_{2} \mathrm{CO}$, have been tested to improve its stability as well as its adsorption capacity, making it suitable for industrial use. The effect of the solution $\mathrm{pH}$ on the adsorption capacity of the alga has been examined to carry out the adsorption experiments at a suitable value of $\mathrm{pH}$. The equilibrium and kinetics of the adsorption process were then evaluated and it was found that both rely on the pre-treatment made to the biomass. Therefore, the equilibrium binding has been described in terms of Langmuir or Freundlich isotherms, depending on the algal pre-treatment, and kinetic data were fitted according to the first order Lagergren model, from which the rate constant of sorption and the equilibrium capacity were determined. These two parameters are dependent on the initial dye concentration, and taking into account these dependencies, simple empirical equations were derived to evaluate the amount of methylene blue removed at any initial concentration and reaction time. 


\section{EXPERIMENTAL}

\subsection{Preparation of the adsorbent}

The adsorbent used was alga Sargassum muticum collected in La Coruña (Galicia, NW Spain). Algae were washed with generous amounts of distilled water and dried in an oven at $60^{\circ} \mathrm{C}$ overnight. Then, they were ground in an analytical mill IKA A 10 and sieved in the size pore range from 0.5 to 1 $\mathrm{mm}$. Finally, the biomass was chemically modified by means of different treatments, which were carried out as follows.

Pre-treatment with $\mathrm{CaCl}_{2}$

A sample of $2.5 \mathrm{~g}$ of dried biomass was treated with $100 \mathrm{~mL}$ of $0.2 \mathrm{~mol} \mathrm{dm}^{-3} \mathrm{CaCl}_{2}$ solution, keeping the solution $\mathrm{pH}$ constant at a value of 5.0 , because it is the optimum $\mathrm{pH}$ value for calcium activation of biomass. The mixture was shaken for $24 \mathrm{~h}$ on a rotary shaker at $175 \mathrm{rpm}$ and room temperature. The biomass was then filtered off followed by washing with deionised water to remove the excess of calcium and it was dried in an oven at $60^{\circ} \mathrm{C}$ for $24 \mathrm{~h} .{ }^{11}$

Pre-treatment with $\mathrm{HCl}$

A constant mass of Sargassum muticum $(2.5 \mathrm{~g})$ was treated with $100 \mathrm{~mL}$ of $0.1 \mathrm{~mol} \mathrm{dm}^{-3} \mathrm{HCl}$ solution for $3 \mathrm{~h}$ at room temperature. The biomass was then filtered off followed by washing with deionised water and it was dried overnight at $60^{\circ} \mathrm{C}$. Then, $400 \mathrm{~mL}$ of $0.1 \mathrm{~mol} \mathrm{dm}{ }^{-3} \mathrm{HCl}$ solution were added to the dried biomass and the previous procedure was repeated. ${ }^{12}$ Formaldehyde cross-linking

$2.5 \mathrm{~g}$ of dried biomass were added to a mixture of $17 \mathrm{~mL} 36 \%$ formaldehyde and $33 \mathrm{~mL}$ of 0.1 mol $\mathrm{dm}^{-3} \mathrm{HCl}$ solution. The mixture was left at room temperature for $1 \mathrm{~h}$ under gentle mixing. The biomass was then filtered off followed by sequential distilled water, $0.2 \mathrm{~mol} \mathrm{dm}^{-3} \mathrm{Na}_{2} \mathrm{CO}_{3}$ and final distilled water washes. It was dried overnight at $60^{\circ} \mathrm{C}$ and finally $2 \mathrm{~h}$ at $110^{\circ} \mathrm{C} .^{13}$

Pre-treated biomass was kept in plastic containers refrigerated at $4^{\circ} \mathrm{C}$ for further use.

\subsection{Dye solution preparation}

The dye used in this study is methylene blue (C.I. 52015; Panreac, dye content 82\%), a cationic thiazine whose chemical structure is shown in Fig 1.

Stock solutions of methylene blue, without further purification, were prepared by dissolving accurately weighed dye in deionised water at a concentration of $1000 \mathrm{mg} \mathrm{L}^{-1}$ and they were diluted when necessary. 


\subsection{Dye adsorption experiments}

In order to carry out the adsorption experiments, a constant mass of alga $(0.1 \mathrm{~g})$ was weighed into a conical flask and $40 \mathrm{~mL}$ of dye solution were added to it. The mixture was shaken at $175 \mathrm{rpm}$ and room temperature for $2 \mathrm{~h}$, when the equilibrium was reached. Then, algae were separated by decantation and the dye concentration was analysed using a spectrophotometer UV/VIS (Varian Cary $100 \mathrm{Bio})$ at $\lambda_{\max } 665 \mathrm{~nm}$. The solutions involved were diluted to proper concentrations, to give absorbancies in the range $0.1-1$, before making the measurements.

Firstly, the effect of the solution $\mathrm{pH}$ on the adsorption capacity of the alga was examined for each treatment, adjusting the $\mathrm{pH}$ value between 1 and 10 by the addition of dilute $\mathrm{HCl}$ or $\mathrm{NaOH}$. Then, the binding capacity of the sorbent was determined varying dye concentration within the range 10$1000 \mathrm{mg} \mathrm{L}^{-1}$ and adjusting the $\mathrm{pH}$ to a value of 5.5. The adsorption capacity of the alga was determined from the concentration difference of the solution, at the beginning and at equilibrium:

$$
q_{e}=\frac{v\left(c_{i}-c_{e}\right)}{1000 m}
$$

where $C_{i}$ and $C_{e}$ are the initial and the equilibrium dye concentrations $\left(\mathrm{mg} \mathrm{L}^{-1}\right), V$ is the volume of solution $(\mathrm{mL})$, and $\mathrm{m}$ is the mass of algae used $(\mathrm{g})$.

Finally, several kinetic experiments were performed as follows: a constant mass of alga (0.125 g) was weighed and transferred into a thermostated cell at $25.0 \pm 0.1^{\circ} \mathrm{C}, 50 \mathrm{~mL}$ of dye solution of different concentrations $\left(50,100,200\right.$ and $500 \mathrm{mg} \mathrm{L}^{-1}$ ) were added to it, and the mixtures were shaken. Aliquots were withdrawn at various time intervals for $4 \mathrm{~h}$ and the concentration of dye was determined as indicated above. The amount of adsorption at time $t, q_{t}\left(\mathrm{mg} \mathrm{g}^{-1}\right)$, was calculated by:

$$
q_{t}=\frac{v\left(C_{i}-C_{t}\right)}{1000 m}
$$

where $C_{t}\left(\mathrm{mg} \mathrm{L}^{-1}\right)$ is the dye concentration at time $t$.

\section{RESULTS AND DISCUSSION}

\subsection{Equilibrium of sorption}

As it is shown in Fig 2, the uptake was unaffected in the $\mathrm{pH}$ range of 4-10 and for $\mathrm{pH}$ values below 2, sorption of methylene blue was less favourable. However, the adsorption capacity for protonated alga, which is the most $\mathrm{pH}$ dependent, at the lower $\mathrm{pH}$ is still about $45 \mathrm{mg} \mathrm{g}^{-1}$. For the adsorption of $\mathrm{Cd}^{2+}$ on Sargassum muticum, ${ }^{14}$ the algal affinity for the metal is explained by an exchange between the metal ions in solution and protons initially present in the biomass; the 
relevance of the negative charge in the algal system has been carefully discussed by Rey-Castro et $\mathrm{a}^{15}$ in a detailed study about the acid-base behaviour of Sargassum muticum biomass directly, and also in connection with the protonation of the most important component of the alga: the alginic acid. ${ }^{16}$ In the case of methylene blue, a pure electrostatic interaction between the negative charge of the alga and the positive charge of the dye cannot be considered the unique mechanism of adsorption. A different type of interaction should account for the adsorption process as an important amount of dye is adsorbed at low pH values, for which the alga is completely protonated; moreover, the increase in the adsorption capacity occurs two $\mathrm{pH}$ units below the algal $\mathrm{pK}_{\mathrm{a}}$, which is 3.85 for a degree of dissociation of $0.5 .^{14}$ These facts suggest the existence of hydrophobic interactions which have been reported by different authors to contribute to the description of the interaction of methylene blue with different kind of surfaces. ${ }^{17-20}$

The equilibrium binding was described in terms of Langmuir and Freundlich isotherms. ${ }^{21,22}$ The Langmuir theory assumes that sorption takes place at specific sites within the adsorbent, which means that once a dye molecule occupies a site, no further adsorption can take place at that site. Therefore, at equilibrium, a saturation point is reached beyond which no further adsorption can occur and the saturation monolayer can be then represented by the following expression:

$$
q_{e}=\frac{q_{\max } b C_{e}}{1+b C_{e}}
$$

where $q_{\max }$ is the maximum amount of adsorption, $b$ is the affinity constant and $C_{e}$ is the solution concentration at equilibrium.

The Freundlich model assumes that the sorption takes place on heterogeneous surfaces and adsorption capacity depends on the concentration of methylene blue at equilibrium according to the exponential expression:

$$
\mathrm{q}_{\mathrm{e}}=\left(\mathrm{bC}_{\mathrm{e}}\right)^{\beta}
$$

where $\beta$ is a heterogeneity factor.

Equation (4) can be linearised as follows:

$$
\log q_{e}=\beta \log b+\beta \log C_{e}
$$

So, the plot of $\log _{e}$ against $\log C_{e}$ of eqn (5) should give a linear relationship, from which $\beta$ and b can be determined from the slope and the intercept respectively.

In the case of Langmuir isotherm, there are two possibilities for the linearisation, each one 
giving different outcomes, besides, these transformations implicitly alter the error structure of data. In view of these considerations, a non-linear fit of experimental data to eqn (3) was done for the sorption of methylene blue on Sargassum muticum treated with $\mathrm{CaCl}_{2}$ and $\mathrm{HCl}$. Figure 3 shows these fits and the linear fit in the inset; adsorption parameters calculated from the non-linear plots are given in Table 1. On the other hand, data for $\mathrm{H}_{2} \mathrm{CO}$ treatment show a better compliance with the Freundlich isotherm (Fig 4). Parameters $b$ and $\beta$ calculated from the linear fit of experimental data are given in Table 1.

Table 2 compares methylene blue sorption using different sorbents and reveals the large adsorption capacity of Sargassum muticum, suggesting that this invasive alga in Europe could be used as a quite effective biosorbent for removing cationic dyes as methylene blue.

\subsection{Determination of the specific surface area}

Moreover, from the maximum adsorption capacity values (Table 1), it is possible to determine the specific surface area of Sargassum muticum biomass according to the following expression ${ }^{23}$

$$
S_{s}=\frac{X_{m} N A_{m}}{M W} \times 10^{-20}
$$

where: $S_{s}=$ specific surface area of the adsorbent $\left(\mathrm{m}^{2} / \mathrm{g}\right)$;

$\mathrm{X}_{\mathrm{m}}=$ monolayer capacity ( $\mathrm{g}$ solute/g solid);

$\mathrm{N}=$ Avogadro's constant $\left(=6.02 \times 10^{23}\right)$;

$A_{m}=$ ionic cross-sectional area of solute $\left((D)^{2}\right)$;

$\mathrm{MW}=$ molecular weight of the solute.

The methylene blue molecular cross section, $A_{m}$, is difficult to assess. In the concentration range used in this work, there is an equilibrium between the monomeric and the dimeric forms of methylene blue in the bulk solution. ${ }^{24}$ On the other hand, when cationic dyes are placed in solutions containing anionic polyelectrolytes they may be adsorbed as induced aggregates. ${ }^{25}$ Assuming that the dimer is formed by monomer units lying flat on the surface ${ }^{26}$ it would occupy double area than the monomer and the specific surface area should be the same independently of the aggregation. However, if the monomer units are joined in a sandwich structure, with the principal molecular axes parallel, ${ }^{24}$ the specific surface area would be a half of that calculated assuming the adsorption of the monomer. A different value should be obtained if it is considered that methylene blue adsorbed molecules are perpendicular to the surface, as has been reported for adsorption on clays. ${ }^{27}$

Different values for the methylene blue cross section have been given in the literature, Hang 
and Brindley, in a study on the adsorption of methylene blue by clay minerals, ${ }^{26}$ considered that the projected areas of the molecule remain between 55 and $130(D)^{2}$, depending on the methylene blue orientation. He and Tebo, ${ }^{28}$ use a value of $55(D)^{2}$, previously employed with clay minerals, in the determination of surface area of spores of the Marine Bacillus sp. Strain SG-1. Results shown in Table 1 were obtained using a value of $108(D)^{2}$ for the ionic cross-sectional area of methylene blue, which was proposed by van den Hul and Lyklema ${ }^{29}$ in a critical study on the determination of specific surface areas by different methods. It is noticeable that these values are much higher than that found using the B.E.T. method $\left(2.86 \mathrm{~m}^{2} / \mathrm{g}\right)$. The reason for this discrepancy may be a different sorption mechanism for nitrogen and dye molecules since in the water-wet state, the alga is swollen and there is a waterfilled porous structure.

\subsection{Kinetics of the sorption process}

As far as kinetics are concerned, it was found that the necessary contact time to reach the equilibrium depends on the initial dye concentration and the adsorption capacity increases with the initial dye concentration in all cases.

In order to elucidate the mechanism of the adsorption process several models were tested. A simple kinetic analysis is the first order Lagergren equation ${ }^{30}$ in the form:

$$
\frac{d q_{t}}{d t}=k_{1}\left(q_{e}-q_{t}\right)
$$

Integrating this equation for the boundary conditions $\mathrm{q}_{\mathrm{t}}=0$ at $\mathrm{t}=0$ and $\mathrm{q}_{\mathrm{t}}=\mathrm{t}$ at $\mathrm{t}=\mathrm{t}$ gives:

$$
\ln \left(q_{e}-q_{t}\right)=\ln q_{e}-k_{1} t
$$

which is the integrated rate law for a first order reaction. Where $q_{e}$ and $q_{t}$ are the sorption capacity at equilibrium and at time $\mathrm{t}$, respectively $\left(\mathrm{mg} \mathrm{g}^{-1}\right)$ and $\mathrm{k}_{1}$ is the equilibrium rate constant of pseudo-first order sorption $\left(\min ^{-1}\right)$.

Equation (7) can be expressed as follows:

$$
q_{t}=q_{e}\left(1-e^{k_{1} t}\right)
$$

In addition, a pseudo-second order equation ${ }^{31-33}$ based on adsorption equilibrium capacity, was tested:

$$
\frac{d q}{d t}=k_{2}\left(q_{e}-q_{t}\right)^{2}
$$

After integration, applying boundary conditions $\mathrm{q}_{\mathrm{t}}=0$ at $\mathrm{t}=0$ and $\mathrm{q}_{\mathrm{t}}=\mathrm{t}$ at $\mathrm{t}=\mathrm{t}$ the eqn (9) becomes: 


$$
q_{t}=\frac{q_{e}^{2} k_{2} t}{1+q_{e} k_{2} t}
$$

which is the integrated rate law for a pseudo-second order reaction. Where $q_{e}$ and $q_{t}$ are the sorption capacity at equilibrium and at time $\mathrm{t}$, respectively $\left(\mathrm{mg} \mathrm{g}^{-1}\right)$, and $\mathrm{k}_{2}$ is the rate constant of pseudosecond order sorption $\left(\mathrm{g} \mathrm{mg}^{-1} \mathrm{~min}^{-1}\right)$.

Equation (10) can be rearranged to obtain a linear form:

$$
\frac{t}{q_{t}}=\frac{1}{k_{2} q_{e}^{2}}+\frac{1}{q_{e}} t
$$

If pseudo-second order kinetics are applicable, the plot of $t / q_{t}$ against $t$ of eqn (11) should give a linear relationship, from which $\mathrm{q}_{\mathrm{e}}$ and $\mathrm{k}_{2}$ can be determined from the slope and the intercept respectively.

The experimental data were fitted to first order and pseudo-second order equations. It was found that the adsorption of methylene blue on Sargassum treated with $\mathrm{CaCl}_{2}$ follows first order kinetics while those for $\mathrm{HCl}$ and $\mathrm{H}_{2} \mathrm{CO}$ treatments show a better compliance with the pseudo-second order equation. However, the equilibrium adsorption capacity values obtained from this equation are not reasonable which suggests that the sorption process is not a pseudo-second order process. The kinetic parameters were calculated by fitting the experimental data to eqn (8) using the non-linear Marquardt algorithm. A non-linear fit was chosen as it has the advantage of providing a value for $\mathrm{q}_{\mathrm{e}}$, which has to be fixed in case of using eqn (7). The values obtained are listed in Table 3 together with the correlation coefficients. The equilibrium adsorption capacity increases with an increase in the initial concentration of methylene blue while the rate constant decreases.

The corresponding linear plots of the values of $\mathrm{q}_{\mathrm{e}}$ and $\mathrm{k}$ against $\mathrm{C}_{\mathrm{i}}$ (initial dye concentration) were regressed to obtain empirical expressions for these values in terms of $C_{i}$. The best fits were found with the following expressions:

$$
\begin{aligned}
& \mathrm{q}_{\mathrm{e}}=\mathrm{dC}_{\mathrm{i}} \\
& \mathrm{k}=\mathrm{aC}_{\mathrm{i}}^{\mathrm{b}}
\end{aligned}
$$

The parameters calculated from these plots are summarised in Table 4 for each treatment of the biomass.

Substituting the expressions above in eqn (8), the rate law for a first order reaction and the relationship between $\mathrm{q}_{\mathrm{t}}, \mathrm{C}_{\mathrm{i}}$ and $\mathrm{t}$ can be represented as: 


$$
q_{t}=d C_{i}\left[1-\exp \left(-a C_{i}^{b} t\right)\right]
$$

This equation can be used to determine in advance the amount of methylene blue removed at any initial concentration and reaction time. The plots of $q_{t} v s$. $t$ are shown in Figs 5,6 and 7 , where symbols represent experimental data and lines are the modelled results according to eqn (14), whose parameters are given in table 4. It is noticeable that experimental data show a good compliance with the proposed equation.

\section{CONCLUSIONS}

In this paper the adsorption behaviour of methylene blue on Sargassum muticum has been evaluated. The equilibrium binding has been described in terms of Langmuir and Freundlich isotherms, depending on the biomass pre-treatment. It is remarkable that the percentage of methylene blue removed is up to $90 \%$, which is higher than that found for other biosorbents and it could be even compared with activated carbon (99.8\% uptake).$^{34}$ Biosorption kinetics have been described by means of the first order Lagergren equation, from which the corresponding kinetics parameters were obtained. These results have led to simple empirical equations, which are very useful to derive the amount of methylene blue removed at any initial concentration and reaction time. It is noteworthy that the equilibrium was achieved, depending on the algal pre-treatment, in $30-60 \mathrm{~min}$, which is similar to values found by other authors for methylene blue sorption on different biosorbents and, in the case of the $\mathrm{H}_{2} \mathrm{CO}$ pre-treated alga, it can be compared with the optimum contact time determined for activated carbon $(35 \mathrm{~min}) .^{34}$

Therefore, this work shows that the invasive alga in Europe, Sargassum muticum, constitutes a promising material to be used as biosorbent which could compete with commercial biosorbents because of its low cost, ready availability and high adsorption capacity. In the future, it could be applied in wastewater treatments, especially of textile effluents.

\section{ACKNOWLEDGEMENTS}

This work was funded by the projects BQU2002-02133 (from the Ministerio de Ciencia y Tecnología of Spain) and PGDIT02TAM10302PR (from the Xunta de Galicia). 
Table 1. Results of methylene blue adsorption isotherm analysis and specific surface areas of the biomass.

\begin{tabular}{|c|c|c|c|c|c|}
\hline Biomass pre-treatment & $q_{\max }\left(\mathrm{mg} \mathrm{g}^{-1}\right)$ & $\mathrm{b}\left(\mathrm{mg}^{-1} \mathrm{~L}\right)$ & $\beta$ & $r^{2}$ & $\mathrm{~S}_{\mathrm{s}}\left(\mathrm{m}^{2} / \mathrm{g}\right)$ \\
\hline $\begin{array}{c}\mathrm{CaCl}_{2} \\
\text { (Langmuir model) }\end{array}$ & $237 \pm 12$ & $0.06 \pm 0.01$ & - & 0.9987 & $412^{a}-206^{b}$ \\
\hline $\begin{array}{c}\mathrm{HCl} \\
\text { (Langmuir model) }\end{array}$ & $279 \pm 4$ & $0.025 \pm 0.001$ & - & 0.9985 & $485^{\mathrm{a}}-242.5^{\mathrm{b}}$ \\
\hline $\begin{array}{c}\mathrm{H}_{2} \mathrm{CO} \\
\text { (Freundlich model) }\end{array}$ & - & $2.51 \pm 0.02$ & $0.997 \pm 0.005$ & 0.9999 & - \\
\hline
\end{tabular}

Table 2. Maximum adsorption capacity of methylene blue on various biosorbents at optimum pH values and room temperature.

\begin{tabular}{ccc}
\hline Sorbent & Sorption capacity $\left(\mathrm{mg} \mathrm{g}^{-1}\right)$ & Reference \\
\hline Activated carbon & 373.9 & Dogan et al. ${ }^{35}$ \\
Sargassum muticum seaweed & 279.2 & Present work \\
Cotton waste & 240 & McKay et al. $^{36}$ \\
Hydrilla verticillata & 198.0 & Low et al. $^{37}$ \\
Moss & 185.0 & Low et al. $^{5}$ \\
Perlite & 162.3 & Dogan et al. $^{35}$ \\
Spirodela polyrrhiza (duckweed) & 144.93 & Waranusantigul et al. $^{38}$ \\
Water hyacinth root & 128.9 & Low et al. $^{5}$ \\
Hexane-extracted spent bleaching earth & 120.5 & Lee et al. $^{39}$ \\
Carbonized spent bleaching earth & 94.5 & Lee et al. $^{39}$ \\
Date pits & 80.3 & Banat et al. $^{40}$ \\
Zeolite & 53.1 & Dogan et al. $^{35}$ \\
\hline
\end{tabular}


Table 3. Kinetic parameters obtained from the first order equation for the sorption of methylene blue on Sargassum muticum.

\begin{tabular}{cccccc}
\hline & {$[\mathrm{MB}]\left(\mathrm{mg} \mathrm{L}^{-1}\right)$} & $\mathrm{MB}$ removed \% & $\mathrm{q}_{\mathrm{e}}\left(\mathrm{mg} \mathrm{g}^{1}\right)$ & $\mathrm{k}_{1}\left(\mathrm{~min}^{-1}\right)$ & $\mathrm{r}^{2}$ \\
\hline \multirow{2}{*}{ Sargassum muticum } & 50 & 97.4 & $19.2 \pm 0.2$ & $0.106 \pm 0.004$ & 0.9968 \\
treated with $\mathrm{CaCl}_{2}$ & 100 & 96.4 & $39.1 \pm 0.2$ & $0.075 \pm 0.001$ & 0.9995 \\
& 200 & 94.2 & $78.8 \pm 0.5$ & $0.067 \pm 0.001$ & 0.9994 \\
& 500 & 90.0 & $197 \pm 6$ & $0.041 \pm 0.003$ & 0.9948 \\
Sargassum muticum & 100 & 98.2 & $15.9 \pm 0.9$ & $0.08 \pm 0.01$ & 0.9290 \\
treated with HCl & 200 & 94.9 & $71 \pm 2$ & $0.054 \pm 0.004$ & 0.9935 \\
& 500 & 92.9 & $131 \pm 5$ & $0.044 \pm 0.004$ & 0.9924 \\
\hline \multirow{2}{*}{ Sargassum muticum } & 100 & 97.0 & $37 \pm 1$ & $0.14 \pm 0.02$ & 0.9678 \\
treated with $\mathrm{H}_{2} \mathrm{CO}$ & 200 & 95.1 & $79 \pm 2$ & $0.10 \pm 0.01$ & 0.9830 \\
& 50 & 98.0 & $19.4 \pm 0.4$ & $0.32 \pm 0.05$ & 0.9715 \\
& 500 & 92.5 & $196 \pm 2$ & $0.113 \pm 0.004$ & 0.9979 \\
\hline
\end{tabular}

Table 4. Parameters calculated from equations (12-13) and the corresponding rate law for each treatment of the biomass.

Pre-treatment

Equation parameters

Rate law

$$
\begin{aligned}
& \mathrm{CaCl}_{2} \quad \mathrm{q}_{\mathrm{e}}=(0.3938 \pm 0.0006) \mathrm{C}_{\mathrm{i}} \quad \mathrm{r}^{2}=1 \quad \mathrm{q}_{\mathrm{t}}=0.3938 \mathrm{C}_{\mathrm{i}}\left[1-\exp \left(-0.5 \mathrm{C}_{\mathrm{i}}^{-0.38} \mathrm{t}\right)\right] \\
& k=(0.5 \pm 0.1) C_{i}^{(-0.38 \pm 0.05)} \quad r^{2}=0.9703 \\
& q_{e}=(0.28 \pm 0.02) C_{i} \quad r^{2}=0.9724 \quad q_{t}=0.28 C_{i}\left[1-\exp \left(-0.23 C_{i}^{-0.27} t\right)\right] \\
& k=(0.23 \pm 0.03) C_{i}^{(-0.27 \pm 0.02)} \quad r^{2}=0.9845 \\
& q_{e}=(0.392 \pm 0.002) C_{i} \quad r^{2}=0.9998 \quad q_{t}=0.392 C_{i}\left[1-\exp \left(-1.5 C_{i}^{-0.45} t\right)\right] \\
& k=(1.5 \pm 0.2) C_{i}^{(-0.45 \pm 0.03)} \quad r^{2}=0.7416
\end{aligned}
$$




\section{FIGURE CAPTIONS}

Figure 1. Chemical structure of methylene blue dye.

Figure 2. Effect of pH on sorption of methylene blue by Sargassum muticum with different treatments.

Figure 3. Langmuir isotherms for the sorption of methylene blue by Sargassum muticum treated with $\mathrm{CaCl}_{2}$ and $\mathrm{HCl}$. Symbols represent experimental points; lines are modelled results according to equation (3).

Figure 4. Freundlich isotherm for the sorption of methylene blue by Sargassum muticum treated with $\mathrm{H}_{2} \mathrm{CO}$. Symbols represent experimental points; the solid line corresponds to the modelled results according to equation (4).

Figure 5. Kinetics for methylene blue uptake by Sargassum muticum treated with $\mathrm{CaCl}_{2}$ at different initial dye concentrations: $50 \mathrm{mg} \mathrm{L}^{-1}$ (ロ), $100 \mathrm{mg} \mathrm{L}^{-1}$ (o), $200 \mathrm{mg} \mathrm{L}^{-1}$ (Î ), and $500 \mathrm{mg} \mathrm{L}^{-1}$ (Ï ). Symbols represent experimental points; lines are modelled results according to equation (14).

Figure 6. Kinetics for methylene blue uptake by protonated Sargassum muticum at different initial dye concentrations: $50 \mathrm{mg} \mathrm{L}^{-1}(\square), 100 \mathrm{mg} \mathrm{L}^{-1}$ (0), $200 \mathrm{mg} \mathrm{L}^{-1}$ (î ), and $500 \mathrm{mg} \mathrm{L}^{-1}$ (Ï ). Symbols represent experimental points; lines are modelled results according to equation (14).

Figure 7. Kinetics for methylene blue uptake by Sargassum muticum treated with $\mathrm{H}_{2} \mathrm{CO}$ at different initial dye concentrations: $50 \mathrm{mg} \mathrm{L}^{-1}$ (口), $100 \mathrm{mg} \mathrm{L}^{-1}$ (o), $200 \mathrm{mg} \mathrm{L}^{-1}$ (Î ), and $500 \mathrm{mg} \mathrm{L}^{-1}$ (Ï ). Symbols represent experimental points; lines are modelled results according to equation (14). 


\section{REFERENCES}

1 Lee CK, Low KS and Chow SW, Chrome sludge as an adsorbent for colour removal. Environ Technol 17: 1023-1028 (1996).

2 Robinson T, McMullan G, Marchant R and Nigam P, Remediation of dyes in textile effluent: a critical review on current treatment technologies with a proposed alternative. Bioresour Technol 77: 247-255 (2001).

3 Graham N, Chen XG and Jayaseelan S, The potential application of activated carbon from sewage sludge to organic dyes removal. Water Sci Technol 43: 245-252 (2001). Kadirvelu K, Kavipriya M, Karthika C, Radhika M, Vennilamani N and Pattabhi S, Utilization of various agricultural wastes for activated carbon preparation and application for the removal of dyes and metal ions from aqueous solutions. Bioresour Technol 87: 129-132 (2003). Low KS, Lee CK and Tan KK, Biosorption of basic dyes by water hyacinth roots. Bioresour Technol 52: 79-83 (1995).

Rajeshwari S and Subburam $\vee$, Activated parthenium carbon as an adsorbent for the removal of dyes and heavy metal ions from aqueous solution. Bioresour Technol 85: 205-206 (2002). Fu $\mathrm{Y}$ and Viraraghavan T, Fungal decolorization of dye wastewaters: a review. Bioresour Technol 79: 251-262 (2001).

Schiewer S and Volesky B, Biosorption processes for heavy metal removal. Environmental Microbe-Metal Interactions 14: 329-362 (2000).

McKay G: Use of adsorbents for the removal of pollutants from wastewater, CRC Press, Boca Raton, (1996).

Critchley AT, Farnham WF, Yoshida T and Norton TA, A bibliography of the invasive alga Sargassum muticum. Bot Mar 33: 551-562 (1990).

11 Matheickal JT, Yu Q and Woodburn GM, Biosorption of cadmium(II) from aqueous solutions by pre-treated biomass of marine alga Durvillaea potatorum. Water Res 33: 335-342 (1999).

12 Davis TA, Volesky B and Vieira RHSF, Sargassum seaweed as biosorbent for heavy metals. Water Res 34: 4270-4278 (2000).

13 Leusch A, Holan ZR and Volesky B, Biosorption of heavy metals ( $\mathrm{Cd}, \mathrm{Cu}, \mathrm{Ni}, \mathrm{Pb}, \mathrm{Zn})$ by chemically-reinforced biomass of marine algae. J Chem Technol Biotechnol 62: 279-288 (1995). 

of cadmium(II) biosorption by the invasive alga in Europe Sargassum muticum. Biotechnol Bioeng in press: (2004).

Rey-Castro C, Lodeiro P, Herrero R and Sastre de Vicente ME, Acid-base properties of brown seaweed biomass considered as a Donnan gel. A model reflecting electrostatic effects and chemical heterogeneity. Environ Sci Technol 37: 5159-5167 (2003).

Rey-Castro C, Herrero R and Sastre de Vicente ME, Gibbs-Donnan and specific ion interaction theory descriptions of the effect of ionic strength on proton dissociation of alginic acid. J Electroanal Chem 564: 223-230 (2004).

17 Guy RD and Narine DR, Organocation speciation. I. A comparison of the interactions of methylene blue and paraquat with bentonite and acid humic. Can J Chem 58: 555-558 (1980). Imamura K, Ikeda E, Nagayasu T, Sakiyama T and Nakanishi K, Adsorption behavior of methylene blue and its congeners on a stainless steel surface. J Colloid Interface Sci 245: 5057 (2002).

19 Mchedlov-Petrossyan NO, Klochkov VK, Andrievsky GV and Ishchenko AA, Interaction between colloidal particles of $\mathrm{C}_{60}$ hydrosol and cationic dyes. Chem Phys Lett 341: 237-244 (2001).

Palit D and Moulik SP, Adsorption of the dyes (methylene blue and acridine orange and their mixtures) from aqueous solutions on cholesterol surface. Colloid J 65: 350-357 (2003).

21 Allen SJ, Gan Q, Matthews R and Johnson PA, Comparison of optimised isotherm models for basic dye adsorption by kudzu. Bioresour Technol 88: 143-152 (2003).

22 McKay G, Blair HS and Gardner JR, Adsorption of dyes on chitin. I. Equilibrium studies. J Appl Polym Sci 27: 3043-3057 (1982).

23 Sharma DC and Forster CF, A preliminary examination into the adsorption of hexavalent chromium using low cost adsorbents. Bioresour Technol 47: 257-264 (1994).

24 Bergmann $\mathrm{K}$ and O'Konski CT, A spectroscopic study of methylene blue monomer, dimer and complexes with montmorillonite. J Phys Chem 67: 2169-2177 (1963).

25 Gessner F, Schmitt CC and Neumann MG, Time-dependent spectrophotometric study of the interaction of basic dyes with clays. 1. Methylene blue and neutral red on montmorillonite and hectorite. Langmuir 10: 3749-3753 (1994). 
Hang PT and Brindley GW, Methylene blue adsorption by clay minerals. Determination of surface areas and cation exchange capacities (clay-organic studies XVIII). Clays and Clay Miner 18: 203-212 (1970).

27 Hahner G, Marti A, Spencer ND and Caseri WRJ, Orientation and electronic structure of methylene blue on mica: A near edge X-ray absorption fine structure spectroscopy study. $J$ Chem Phys 104: 7749-7757 (1996).

28 He LM and Tebo BM, Surface charge properties of and $\mathrm{Cu}(\mathrm{II})$ adsorption by spores of the marine bacillus sp. Strain SG-1. Appl Environ Microbiol 64: 1123-1129 (1998).

29 van den Hul HJ and Lyklema J, Determination of specific surface areas of dispersed materials. Comparison of the negative adsorption method with some other methods. J Am Chem Soc 90: 3010-3015 (1968).

30 Lagergren S, About the theory of so-called adsorption of soluble substances. Kungliga Svenska Vetenskapsakademiens Handlingar 24: 1-39 (1898).

31 Ho YS, Wase DAJ and Forster CF, Kinetic studies of competitive heavy metal adsorption by sphagnum moss peat. Environ Technol 17: $71-77$ (1996).

32 Ho YS and McKay G, A comparison of chemisorption kinetic models applied to pollutant removal on various sorbents. Transactions of the Institution of Chemical Engineers 76: 332340 (1998).

33 Ho YS and McKay G, The kinetics of sorption of divalent metal ions onto sphagnum moss peat. Water Res 34: 735-742 (2000).

34 Kannan $\mathrm{N}$ and Sundaram MM, Kinetics and mechanism of removal of methylene blue by adsorption on various carbons-a comparative study. Dyes and Pigments 51: 25-40 (2001).

35 Dogan $\mathrm{M}$, Alkan $\mathrm{M}$ and Onager $\mathrm{Y}$, Adsorption of methylene blue from aqueous solution onto perlite. Water Air Soil Pollut 120: 229-248 (1998).

36 McKay G, Ramprasad G and Pratapamowli P, Equilibrium studies for the adsorption of dyestuffs from aqueous solution by low-cost materials. Water Air Soil Pollut 29: 273-283 (1986).

37 Low KS, Lee CK and Heng LL, Sorption of basic dyes by Hydrilla verticillata. Environ Technol 14: $115-124(1993)$.

38 Waranusantigul $\mathrm{P}$, Pokethitiyook $\mathrm{P}$, Kruatrachue M and Upatham ES, Kinetics of basic dye 
(methylene blue) biosorption by giant duckweed (Spirodela polyrrhiza). Environ Pollut 125: 385-392 (2003).

39 Lee CK, Low KS and Chung LC, Removal of some organic dyes by hexane-extracted spent bleaching earth. J Chem Technol Biotechnol 69: 93-99 (1997).

40 Banat F, Al-Asheh S and Al-Makhadmeh L, Evaluation of the use of raw and activated date pits as potential adsorbents for dye containing waters. Process Biochem 39: 193-202 (2003). 